\title{
Model for Solid Electrolyte Gas Electrode Reaction Kinetics; Key Concepts, Basic Model Construction, Extension of Models, New Experimental Techniques for Model Confirmation, and Future Prospects \\ Junichiro MIZUSAKI*
}

Prof. Emeritus, Tohoku University; Now with Atelier Mizusaki, 2-20-7-204 Nishifuna, Funabashi 273-0031, Japan

* Corresponding author: mizusaki@tagen.tohoku.ac.jp

\begin{abstract}
In order to survey history and state of art of theoretical and kinetic studies of gas electrode reaction on solid oxide electrolyte, overview was made on the research works reported by the author and his co-investigators. Through reviewing their works, frontier of research is clarified. It was shown that electrode reaction is controlled by nonfaradaic chemical reaction process, and the nature of the overpotential is the chemical potential deviation of the interface from equilibrium state. Mechanical stress at the electrode/solid electrolyte interface is considered varying with the overpotential. Importance is emphasized for mechano-electrochemistry, the field to study the relationship of electrochemistry and mechanical property of the electrochemical cells.
\end{abstract}

(C) The Electrochemical Society of Japan, All rights reserved.

Keywords : Solid Electrolyte, Gas Electrode Reaction Kinetics, Chemical Capacitance, Mechano-electrochemistry

\section{Introduction}

From early stage of basic researches for application of solid oxide electrolytes such as stabilized zirconia and doped ceria, reaction kinetics of the gas electrodes on solid electrolytes has been one of the major issues in the field of solid state ionics. It was already known that the performance of solid state electrochemical cells such as fuel cells, steam electrolyzer, oxygen pumps and chemical sensors are strongly affected by the chemical components and morphology of electrode materials of the gas electrodes in these cells. To improve the electrode performance, kinetic of the electrode reaction is very important because it tells the important points of the electrode structure to enhance the electrode performance and thus give us the direction how to improve the performance. Variety of research groups were involved to reveal the gas electrode kinetics. ${ }^{1-15}$ However, in the late 1970s when the author and the co-investigators started studies on the kinetics of solid electrolyte gas electrodes, independent research groups proposed different reaction models and no research group succeeded to explain the performance of fuel cells and chemical sensors under the same theorem.

For the first, the author aimed to explain the electrochemical performance of Pt electrodes on stabilized zirconia and the response of potentiometric oxygen gas sensors utilizing Pt electrode and stabilized zirconia electrolyte, and started the series of studies. ${ }^{16-20}$

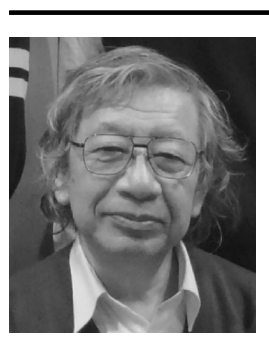

Junichiro Mizusaki (Prof. Emeritus, Tohoku University)

Born on June 4, 1947. Graduated from Graduate School of Univ. Tokyo on March 1975, earned degree of Dr. Engineering. Joined Faculty of Engineering, Univ. Tokyo from 1975 to 1986 as Assistant Prof., Yokohama National Univ. from 1986 to 1994 as Associate Prof. and Tohoku Univ. as Prof. from 1994 to 2012. Served as President of SOFC Society Japan from 2004 to 2012 and President of Solid State Ionics Society of Japan from 2006 to 2010. Chaired $19^{\text {th }}$ International Conference of Solid State Ionics in Kyoto on June 2012. Awarded Takei Prize from ECSJ in 2010. His major is Solid State Ionics and Environmental Energy Science.
Then, the work extended to variety of areas. The results are reported mainly in reviewed regular papers. ${ }^{16-59}$ However, some important results are published only in proceedings papers. ${ }^{60-76}$ Most of these proceedings papers are in preliminary forms but a few of them turned to be the final ones because they were published in volumes of monographs or commercialized books. ${ }^{60-62,73-76}$ Some of the proceedings papers are comprehensive ones. ${ }^{61,75}$

The author has also published several review papers in journals and as chapters of books ${ }^{77-89}$ on the studies of electrode reaction kinetics. However, these review papers tended to focus on the limited topics such as the first kinetic model by the authors for platinum electrodes, selected topics for new kinetics and phenomena of SOFC electrodes, and some new techniques for kinetic studies. The overview for the whole works of the author and the coinvestigators for the electrode reaction kinetics has not yet been made.

The purpose of this comprehensive paper is to show the overview of the research works of the present author and his co-investigators on the variety of electrode reaction kinetics, relaxation processes, and new tools, with the precise references for easier access to the original and detailed reports on iterative topics. Through this review, direction for the future important research area will be revealed. Table 1 summarizes the whole studies of the present author and his co-investigators by the number of the papers in the references; the items in the column show the materials and components of the gas electrodes and those in the row show the applied experimental techniques as well as the proposed models in the iterative papers. Figure 1 shows the schematics of the electrode reaction path discussed in this paper with the list of gaseous components, electrode materials, electrode morphologies, electrolytes, interlayers, and proposed models listed in Table 1.

Some of the research works by the groups other than the present author's were quite important for the present author to establish the proposed reaction models in Table 1. These works are listed in the references. ${ }^{90-96}$ Recently, there are many review papers published on the SOFC electrode materials and reactions. Here, the reviews by Adler $^{97}$ and by Tsipis, Vladislav and Kharton ${ }^{98}$ are listed in the reference as the representative examples. 
Table 1. Materials, tools and properties of solid electrolyte gas electrodes studied by the present authors for kinetics studies. The iterative studies are indicated by the reference numbers. ${ }^{16-76}$ Ref. 75 is not listed in the table because it is the review paper with the discussion on the Butler-Volumer equation.

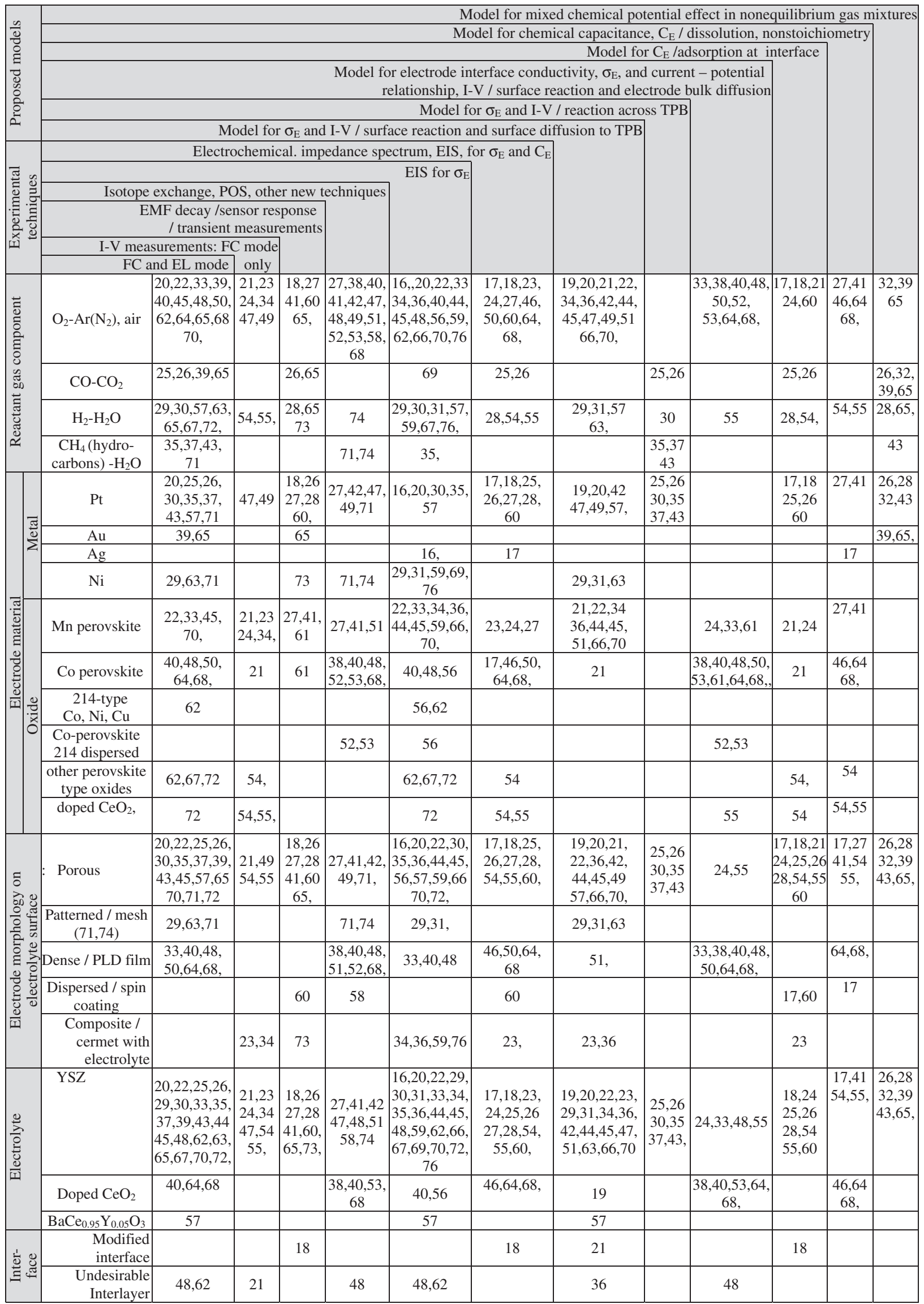




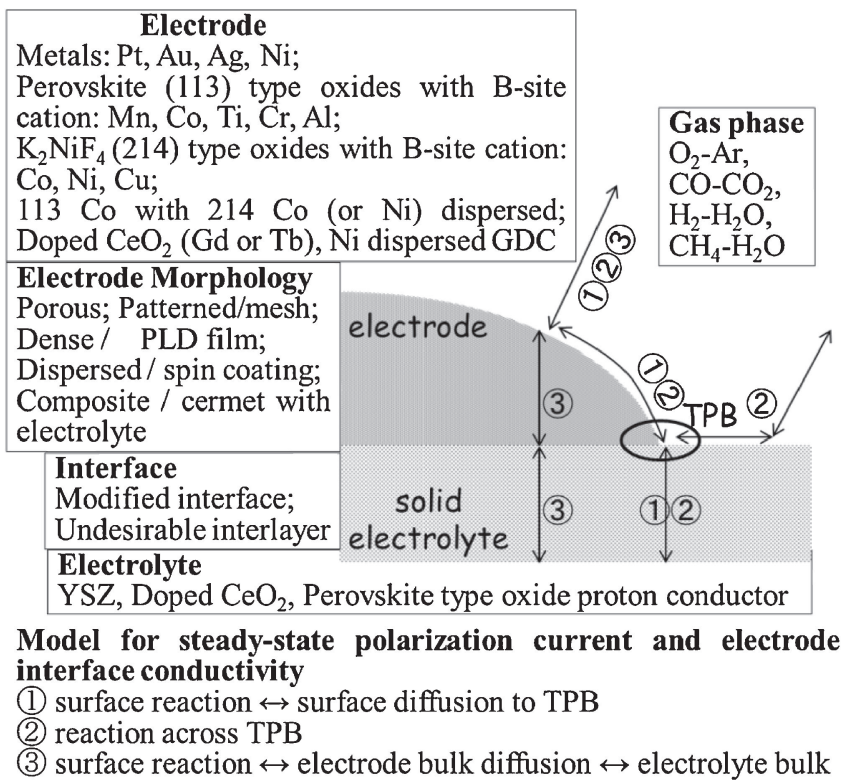

Figure 1. Schematics of the electrode reaction path with the relationships to the works itemized in Table 1.

\section{Theory on non-Faradaic Rate Determining Process and Butler-Volmer Equation}

In Table 1 and Fig. 1, there is no charge transfer process explicitly shown. The author have concluded that the rate limiting process of the solid electrolyte gas electrode reaction is nonfaradaic chemical process. This conclusion was led from the following two types of consideration: One is phenomenological insight ${ }^{19,60,75,89}$ and another is the reconsideration of the ButlerVolmer equation. ${ }^{75,87,89}$

\subsection{Phenomenological consideration; aqueous vs. solid electrolyte electrode reaction}

Let us consider a reactant gas molecule adsorbed on the surface of electrode and dissociated on the surface to form ad-atoms. The adatom vibrates on the surface and the bonding length with the lattice atoms just below the layer of adsorbed atoms may vary with the vibration. We call these lattice atoms as the surface atoms here after. The magnitude of this vibration is considered much larger than that between the lattice atoms. When the bonding between the ad-atom and the surface atom is as short as that between the lattice atoms, strong charge transfer may take place between the ad-atom and the surface atom nearest to the ad-atom. When the bonding length becomes long, the bonding becomes weaker and the charge transfer becomes weaker. When the ad-atoms are incorporated in the bulk of oxide electrode, they are surely fully ionized. When they diffuse on the surface, they vibrate between the ionized state and the state rather close to the atomic state. That is, charge transfer takes place rather easily on the solid electrolyte gas electrode system, simultaneously with the adsorption without particularly large excited state.

This is quite different from the case of aqueous electrode where charge transfer process is considered often the rate limiting one and the most activated point in the reaction path. The difference is caused by the hydration of ions in aqueous systems. To exchange charges with the electrode, the ions in aqueous solutions comes out from hydrated state. After charge transfer, it goes back to hydrated state again. These dehydration-rehydration process takes place simultaneously with the charge transfer. The process may require highly activated state. In short, the electrode reaction rate controlled by the charge transfer reaction process may be a characteristic phenomenon to polar solvents. ${ }^{19}$

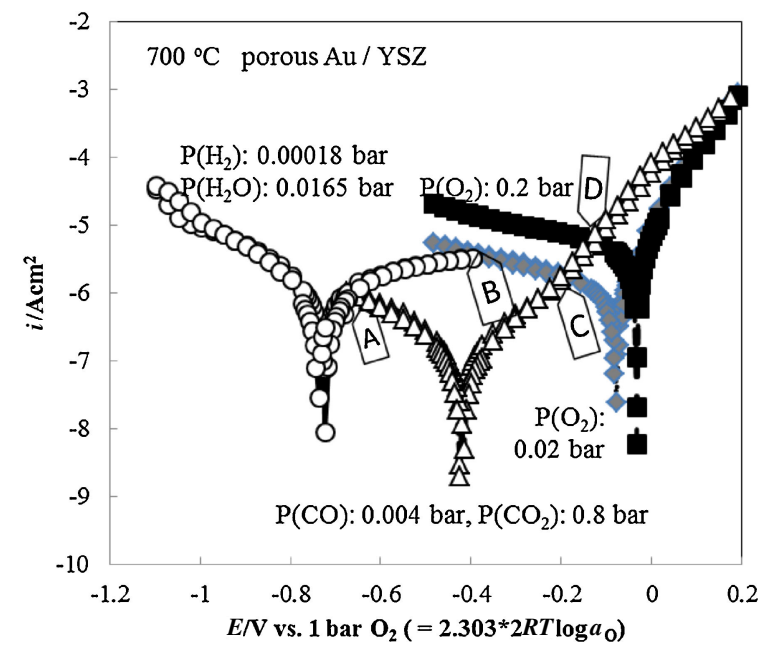

Figure 2. (Color online) Typical examples of steady-state electrode polarization curve (logarithm of current vs. electrode potential relationship) for gas electrodes. ${ }^{65}$ In each "Y" shaped $\log |i|$ vs. $E$ curves, the left side current is actually negative. A three-terminal method was used for the polarization measurements; the working electrode was porous $\mathrm{Au}$ electrode on YSZ and the counter and reference electrodes are porous $\mathrm{Pt}$ in controlled $\mathrm{O}_{2}(\mathrm{~g})$ atmospheres. The electrode potential in the figure was obtained after compensation of the electrolyte resistance. The detailed calculation procedures for the electrode potential were given in Ref. 19.

\subsection{Physical meaning of Butler-Volmer type relationship \\ 2.2.1 Conventional understanding}

In spite of the above consideration, not a few researchers still conclude the solid electrolyte gas electrode reaction controlled by charge transfer reactions. It may be because the observed reaction rate apparently obeys the Butler-Volmer equation and conventional text books of electrochemistry usually tell that the reaction is controlled by the charge transfer process at the electrolyte-electrode interface when the Butler-Volmer equation holds.

Some example of polarization curves are shown in $\log |i|$ vs. $E$ plot in Fig. 2. ${ }^{65}$ Here, $i$ is current density and $E$ is the electrode potential. Each polarization curve shows "Y" shape in the logarithmic scale. In each "Y" shaped polarization curve, the left side current is actually negative. The potential corresponding to the sharp bottom of "Y" is considered the equilibrium potential, $E_{\text {eq }}$, for the gas composition corresponding to the representative polarization curve. You may easily find that the current vs. $E$ relationship apart from the equilibrium potential essentially obey Tafel equation,

$$
\log |i|=\mathrm{a}+\mathrm{b}\left(E-E_{\text {eq }}\right)=\mathrm{a}+\mathrm{b} \eta
$$

where, $\mathrm{a}$ and $\mathrm{b}$ are constants and

$$
\eta=E-E_{\mathrm{eq}}
$$

is called overpotential. Since both anodic and cathodic polarization in Fig. 2 follow the Tafel equation, you may find that the polarization curves in Fig. 2 can be fitted to the Butler-Volmer equation given by

$$
i=i_{0}[\exp \{\operatorname{n\alpha } \eta F /(R T)\}-\exp \{-\mathrm{n}(1-\alpha) \eta F /(R T)\}]
$$

where $i_{0}$ is a constant called exchange current, $\alpha$ is a constant called a transfer coefficient and $\mathrm{n}$ is the number of electrons exchanged in the rate determining charge transfer reaction. Then, in spite of the discussion in 2.1, people tend to be driven to believe that the rate determining reaction is the charge transfer one.

Some people may find that the data in Fig. 2 deviates considerably from Eq. (3). Such the further discussion is, however, beyond the scope of the present paper. Details were given in Ref. 65 . 


\subsubsection{Butler-Volmer type relationship form chemical reaction controlled kinetics ${ }^{75,87,89}$}

Let us consider a chemical reaction with $p$ moles of species A and $\mathrm{q}$ moles of species $\mathrm{B}$ react to form the products of $\mathrm{r}$ moles of species $\mathrm{C}$ and $\mathrm{s}$ moles of species $\mathrm{D}$. The chemical equation and the rate equation for this reaction can be expressed by the equations,

$$
\mathrm{pA}+\mathrm{qB} \rightarrow \mathrm{rC}+\mathrm{sD}
$$

and

$$
v=k a_{\mathrm{A}}{ }^{\mathrm{p}} a_{\mathrm{B}}{ }^{\mathrm{q}}-k^{\prime} a_{\mathrm{C}}{ }^{\mathrm{r}} a_{\mathrm{D}}{ }^{\mathrm{s}}
$$

where $v$ is the reaction rate, $k$ and $k^{\prime}$ are reaction constants and $a_{\mathrm{A}}$, $a_{\mathrm{B}}, a_{\mathrm{C}}$ and $a_{\mathrm{D}}$ are activities of $\mathrm{A}, \mathrm{B}, \mathrm{C}$, and D, respectively. You can rewrite the activity of chemical species $\mathrm{X}(\mathrm{X}=\mathrm{A}, \mathrm{B}, \mathrm{C}, \mathrm{D})$ by the chemical potential of $\mathrm{X}, \mu_{\mathrm{X}}$, by the equation

$$
\mu_{\mathrm{X}}-\mu_{\mathrm{X}}{ }^{\mathrm{o}}=R T \ln a_{\mathrm{X}} \quad \text { or } \quad a_{\mathrm{X}}=\exp \left\{\left(\mu_{\mathrm{X}}-\mu_{\mathrm{X}}{ }^{\mathrm{o}}\right) /(R T)\right\}
$$

where $\mu_{\mathrm{X}}{ }^{0}$ is the chemical potential of $\mathrm{X}$ at the standard state at which $a_{\mathrm{X}}$ is defined as unity. Using chemical potential in Eq. (6), we can rewrite Eq. (5) as follows.

$$
\begin{aligned}
v= & k \exp \left[\left\{\left(\mathrm{p} \mu_{\mathrm{A}}+\mathrm{q} \mu_{\mathrm{B}}\right)-\left(\mathrm{p} \mu_{\mathrm{A}}{ }^{\mathrm{o}}+\mathrm{q} \mu_{\mathrm{B}}{ }^{\mathrm{o}}\right)\right\} /(R T)\right] \\
& -k^{\prime} \exp \left[\left\{\left(\mathrm{r} \mu_{\mathrm{C}}+\mathrm{s} \mu_{\mathrm{D}}\right)-\left(\mathrm{r} \mu_{\mathrm{C}}{ }^{\mathrm{o}}+\mathrm{s} \mu_{\mathrm{D}}{ }^{\circ}\right)\right\} /(R T)\right] \\
= & k_{\mathrm{R}} \exp \left\{\left(\mathrm{p} \mu_{\mathrm{A}}+\mathrm{q} \mu_{\mathrm{B}}\right) /(R T)\right\} \\
& -k_{\mathrm{R}}{ }^{\prime} \exp \left\{\left(\mathrm{r} \mu_{\mathrm{C}}+\mathrm{s} \mu_{\mathrm{D}}\right) /(R T)\right\}
\end{aligned}
$$

Here, $\left.k_{\mathrm{R}}=k \exp \left\{-\left(\mathrm{p} \mu_{\mathrm{A}}{ }^{\mathrm{o}}+\mathrm{q} \mu_{\mathrm{B}}{ }^{\mathrm{o}}\right)\right\} /(R T)\right\}$ and $k_{\mathrm{R}}{ }^{\prime}=k^{\prime} \exp \left\{-\left(\mathrm{r} \mu_{\mathrm{C}}{ }^{\mathrm{o}}+\right.\right.$ $\left.\left.\mathrm{s} \mu_{\mathrm{D}}{ }^{\mathrm{o}}\right) /(R T)\right\}$.

Using, chemical potential in Eq. (6), Gibbs free energy change $\Delta G$ for the reaction in Eq. (4), can be expressed by

$$
\Delta G=\left(\mathrm{r} \mu_{\mathrm{C}}+\mathrm{s} \mu_{\mathrm{D}}\right)-\left(\mathrm{p} \mu_{\mathrm{A}}+\mathrm{q} \mu_{\mathrm{B}}\right)=-\mathrm{z} F U
$$

Here, $U$ is the Nernst EMF of the cell if you prepare the electrochemical cell using the reaction in Eq. (4), and $\mathrm{z}$ is the molar number of electrons which contribute the reaction in Eq. (4).

When the reaction is in equilibrium, $\Delta G$ is zero and $v=0$ as well. That is, from Eq. (7), we have

$$
k_{\mathrm{R}}=k_{\mathrm{R}}{ }^{\prime} \text {. }
$$

When $\Delta G$ is negative, Eq. (8) proceeds. $\Delta G$ becomes negative either the chemical potential of the reactant increases or the chemical potential of the product decrease. In other words, when we give $\Delta G$ to proceeds the reaction, a portion $\alpha$ of $\Delta G$ contributes to increase the chemical potential of the reactants and the other portion $(1-\alpha)$ to decrease the chemical potential of products. Then, we can rewrite the rate equation as

$$
v=k_{\mathrm{R}}[\exp \{\alpha z F U /(R T)\}-\exp \{-(1-\alpha) \mathrm{ZFU} /(R T)\}]
$$

Equation (10) is identical to Eq. (3), showing that the rate of any chemical reaction can be expressed in terms of the Butler-Volmer type equation.

When we apply this equation to the gas electrode half-cell reaction, $\Delta G$ is the difference in the oxygen chemical potential under equilibrium and under steady-state electrochemical reaction. This can be measured from the chemical overpotential described next.

\subsection{Physical meaning of overpotential ${ }^{19}$}

Figure 3 shows the schematic model for the system with a gas electrode as the working electrode, WE, and a reference electrode, $\mathrm{RE}$, under cathodic polarization. Under equilibrium condition, $P\left(\mathrm{O}_{2}\right)$ in the gas phase and oxygen activity, $a_{\mathrm{O}}$, in the solid electrolyte, $\mathrm{SE}$, at WE/SE interface is in equilibrium: $P\left(\mathrm{O}_{2}\right)^{1 / 2}=a_{\mathrm{O}}(\mathrm{eq})$. Under a steady-state polarization, $a_{\mathrm{O}}$ is different from $a_{\mathrm{O}}(\mathrm{eq})$. On the other hand, $a_{\mathrm{O}}$ at the RE/SE interface is always in equilibrium with $P\left(\mathrm{O}_{2}\right)$ (ref), provided that $P\left(\mathrm{O}_{2}\right)$ (ref) is well defined and the RE

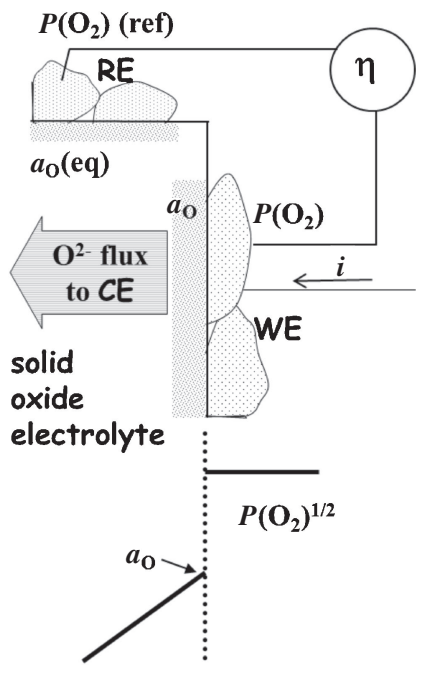

Figure 3. Physical meaning of the potential observed at the reference electrode. ${ }^{19}$

electrode is highly active to keep equilibrium between the gas-phase of RE and RE/SE interface, in other words, RE behaves ideal.

When the potential of gas phase of RE, $P\left(\mathrm{O}_{2}\right)($ ref $)$ is the same to the reactant $P\left(\mathrm{O}_{2}\right), a_{\mathrm{O}}(\mathrm{ref})=P\left(\mathrm{O}_{2}\right)^{1 / 2}$. Then, the difference in the equilibrium state and the steady state can be observed by the difference between $a_{\mathrm{O}}(\mathrm{RE})$ and $a_{\mathrm{O}}(\mathrm{WE})$, or the potential difference, $\eta$, between WE and RE.

$$
2 F \eta_{\text {chem }}=R T \ln \left\{a_{\mathrm{O}} / a_{\mathrm{O}}(\mathrm{eq})\right\}
$$

We may call this overpotential as chemical overpotential, $\eta_{\text {chem. }}$. Under the stady-state polarization, an electrostatic potential difference due to oxide ion transport appears between the WE interface and RE interface, similar to the procedures in aqueous electrolyte electrodics. Therefore, ohmic resistance compensation is necessary in the analysis of experimental data. ${ }^{19,30,77,80}$ When $P\left(\mathrm{O}_{2}\right)($ ref $)$ is set different from $P\left(\mathrm{O}_{2}\right)$ of the reactant gas at WE, compensation for the difference is necessary to attain the correct $\eta_{\text {chem }}$.

\section{Standardized Experimental Procedures and Fundamental Techniques for Study of Gas Electrode Kinetics in Solid Electrolyte System}

\subsection{Importance of gas phase chemical potential control and reference electrode atmosphere}

After the initial works, ${ }^{16,17}$ the author and co-investigators found a very high probability for the reaction at the gas electrode to be controlled by non-Faradic chemical processes. That is, chemical parameters are very important, as described in 2.3. Then, all the experimental works by the present author's group have been done under carefully controlled atmospheres. When the three-terminal method was employed, particular care was paid so as to keep the atmosphere of reference electrode under well defined conditions. When the performance of the counter electrode, CE, is poor, large polarization would take place at the CE/Solid Electrolyte (SE) interface, resulting in large chemical potential deviation in the electrolyte near the CE/SE interface. This deviation may eventually affect the chemical potential in the vicinity of RE.

Ironically, $\mathrm{RE}$ and $\mathrm{CE}$ are required theoretically to behave ideally, that is, better than working electrode. Discussion on the performance of reference and counter electrodes was made in several papers, ${ }^{19,27,30,35}$ particularly in relation to gas sensors, ${ }^{18,26,28,39}$ and new techniques. ${ }^{40,51,68}$

Gas phase chemical potential is sensitive to impurity gas particularly when the reactant gas is much diluted or gas mixing 
ratio of oxidant and reductant gases is very far from unity. Therefore, gas flow rate is one of the important parameters to estimate the effect of impurity gas contamination from tubing system. ${ }^{26,28}$

\subsection{Fundamental electrochemical techniques employed in the present researches}

Similar to conventional studies on aqueous electrolyte systems, fundamental techniques are steady state polarization measurements and transient or relaxation techniques. Most of the research works were done using three-terminal methods. For polarization, galvanostatic as well as potentiostatic methods were employed according to the circumstance of experimental set-up and experimental procedures. For example, when there was difficulty in preparing the high performance stable reference electrode, galvanostatic technique was employed and careful measurements with high input impedance electrometers were made on the EMF between WE and RE. ${ }^{40,51}$ When current interruption is required after the steady state being attained, galvanostatic methods were also employed. ${ }^{41}$

Ac impedance spectroscopy was also frequently used. In early stages, impedance methods are applied only for the conditions without dc current. ${ }^{16-26,60-62}$ With the improvement of impedance analyzers, ac impedance measurements were going to be applied under dc bias as well as non-bias conditions. For the evaluation of impedance, the author's group essentially considers three types of parameters.

The first type is the steady-state parameters, wire resistance, bulk electrolyte resistance, and the resistance due to electrode reaction process, $R_{\mathrm{E}}$. For the evaluation of stead-state electrode reaction process, electrode reaction resistance is usually employed. The author considered it better to use the reactivity of the electrode for the evaluation. Reactivity is considered proportional to conductance, inversely proportional to resistivity. Then, the author proposed to use the inverse of electrode resistance for a unit area of the electrode/electrolyte interface, naming it as electrode interface conductivity, $\sigma_{\mathrm{E}}$. That is,

$$
\sigma_{\mathrm{E}}=1 /\left(A R_{\mathrm{E}}\right)
$$

where $A$ is the area of the electrode/electrolyte interface. ${ }^{16,19,60}$

Others are time dependent polarization phenomena. One is related to the current decay observed after the application of potentiostatic polarization potential. It can be described by the capacitive component of the ac electrode impedance. The other is related to the current increase with time observed after the application of potentiostatic polarization potential. It is related to the inductive component of the ac impedance. The author often discusses the capacitive component for the electrode process, expressed by $C_{\mathrm{E}}$, to describe the chemical reaction controlled kinetics, namely chemical capacitances. ${ }^{16-18,60}$ Further details will be described in the sections 4 and 5 .

The electromotive force, EMF, of the cell and its time change was found to give also very important parameters of electrode kinetics and key issue to solve the reaction mechanism. ${ }^{18,26,28,35,39,43,60,65}$

\subsection{Morphology as controllable parameter for electrode kinetic study}

As shown in Fig. 1, the reaction path in the electrode differs by electrode materials, electrolyte materials, and reactant gases. Particularly large effect appears by the electrode morphology of porous electrodes. In order to elucidate these reaction paths, one of the best ways is to compare the electrochemical data as functions of morphological parameters of the electrodes or electrode/ electrolyte interfaces. Also, the author found that $C_{\mathrm{E}}$ and the related relaxation phenomena are very sensitive to the electrode morphology. ${ }^{16-18,23-26,28,60}$ Several original approaches were made by the present author. Details are discussed in the sections 5 and 7 .

\section{Models for the Reaction Path}

\subsection{Surface reaction (dissociative adsorption)—surface diffusion-Triple Phase Boundary, TPB \\ 4.1.1 Basic theory ${ }^{19}$}

In oxygen containing atmospheres, reactivity of Pt electrodes, represented by $\sigma_{\mathrm{E}}$, show unique $P\left(\mathrm{O}_{2}\right)$ dependence. At low $P\left(\mathrm{O}_{2}\right)$ or high temperatures, $\sigma_{\mathrm{E}}$ increases with $P\left(\mathrm{O}_{2}\right)^{1 / 2}$ while at temperatures below $700^{\circ} \mathrm{C}$ and rather high $P\left(\mathrm{O}_{2}\right), \sigma_{\mathrm{E}}$ is proportional to $P\left(\mathrm{O}_{2}\right)^{-1 / 2}$. In between the two regions exists a broad maximum. Such behavior was successfully explained by assuming Langmuir-type oxygen adsorption on Pt surface and surface diffusion of adsorbed oxygen takes place by surface site hopping, exchanging the neighboring sites I and II between an adsorbed oxygen atom, $\mathrm{O}_{\mathrm{ad}}$, and a surface vacant site, $\mathrm{V}_{\mathrm{ad}}$.

$$
\mathrm{O}_{\mathrm{ad}}(\mathrm{I})+\mathrm{V}_{\mathrm{ad}}(\mathrm{II}) \rightarrow \mathrm{V}_{\mathrm{ad}}(\mathrm{I})+\mathrm{O}_{\mathrm{ad}}(\mathrm{II})
$$

This model can be extended to variety of cases. When the surface diffusion is very slow, the path of oxygen supply to the Pt surface in the vicinity of TPB may be limited only from the gas phase and the dissociative adsorption of $\mathrm{O}_{2}$ on $\mathrm{Pt}$ will be the rate limiting process. ${ }^{19}$

In reducing atmosphere with $\mathrm{H}_{2} / \mathrm{H}_{2} \mathrm{O}$ gas, the surface of Pt or $\mathrm{Ni}$ is covered not by $\mathrm{O}_{\mathrm{ad}}$ but by $\mathrm{H}_{\mathrm{ad}}$. In such cases, dissociative adsorption of $\mathrm{H}_{2}(\mathrm{~g})$ and the surface diffusion of $\mathrm{H}_{\mathrm{ad}}$ to TPB becomes the important reaction pathway. Detailed analysis was made on $\mathrm{Ni} / \mathrm{YSZ}_{\text {system }}{ }^{29,63,88}$ and $\mathrm{Pt} / \mathrm{BaCe}_{0.95} \mathrm{Y}_{0.05} \mathrm{O}_{3-\delta}$ system. ${ }^{57}$

\subsubsection{Effect of oxygen nonstoichiometry of electrode oxide on} surface diffusion

As the reaction proceeds, the oxygen chemical potential gradient on the surface gradually affects inside of the electrode materials. ${ }^{41}$ In $\mathrm{La}_{1-x} \mathrm{Sr}_{x} \mathrm{MnO}_{3+\delta}$, nonstoichiometry varies under ordinary to slightly reduced atmospheres in the range of roughly $-0.01<\delta<0.17$. $^{99}$ The defect in apparently oxygen excess composition is La vacancy while that in oxygen deficient composition is oxygen vacancy. ${ }^{99}$ Under the condition that the nonstoichiometry variation in $\mathrm{La}_{1-x} \mathrm{Sr}_{x} \mathrm{MnO}_{3+\delta}$ is negligibly small, we find that $\sigma_{\mathrm{E}}$ is proportional to $P\left(\mathrm{O}_{2}\right)^{1 / 2} \cdot 22,44,45,66,70$ With the increase in oxygen content, $\sigma_{\mathrm{E}}$ becomes smaller than the value expected from the $P\left(\mathrm{O}_{2}\right)^{1 / 2}$ relationship. ${ }^{44,45,66}$ Similarly, ac impedance measurements under polarization revealed that $\sigma_{\mathrm{E}}$ varies with not only the gas phase $P\left(\mathrm{O}_{2}\right)$ but also by the electrode potential determined by the chemical overpotential defined by Eq. (11). ${ }^{45,70}$

The lattice parameter decreases with the increase in oxygen content, irrespective of defect species. ${ }^{100,101}$ It is considered that the lattice parameter decrease is related to the decrease in the surface diffusivity of $\mathrm{O}_{\mathrm{ad}}$. With the decrease in the bonding length, the bonding becomes stronger. Then, more activation energy is required for the migration of $\mathrm{O}_{\mathrm{ad}}$, resulting in the decrease in diffusivity. Other nonstoichiometry effect will be discussed in 4.3 and 5 .

\subsection{Reaction between adsorbed species across}

TPB, ${ }^{25,26,30,35,37,43}$ reaction with Pt electrode and stabi-

lized zirconia electrolyte under reduced atmospheres

Under reduced atmospheres with $\mathrm{CO}-\mathrm{CO}_{2}$ or $\mathrm{H}_{2}-\mathrm{H}_{2} \mathrm{O}$, the coverage of $\mathrm{O}_{\mathrm{ad}}$ on the surface of Pt becomes low. Then, to progress the redox reaction, $\mathrm{H}_{\mathrm{ad}}$ or $\mathrm{CO}_{\mathrm{ad}}$ on Pt must pick up oxidant species from the oxide electrolyte surface across TPB. When the electrolyte is stabilized zirconia, $\mathrm{SZ}$, the adsorbed species in reduced atmospheres with $\mathrm{CO}-\mathrm{CO}_{2}$ is $\mathrm{O}_{\mathrm{ad}}$ at the higher $P\left(\mathrm{O}_{2}\right)$ and adsorbed carbon, $\mathrm{C}_{\text {ad }}$, in the lower $P\left(\mathrm{O}_{2}\right) \cdot{ }^{25}$ In the $\mathrm{H}_{2}-\mathrm{H}_{2} \mathrm{O}$ atmospheres, the adsorbed species on $\mathrm{SZ}$ is $\mathrm{O}_{\mathrm{ad}}, \mathrm{OH}_{\mathrm{ad}}$, and $\mathrm{H}_{2} \mathrm{O}_{\mathrm{ad}}$ from the higher to the lower $P\left(\mathrm{O}_{2}\right){ }^{30}$ The concluded rate determining reactions taking place between the adsorbed species on Pt surface and that on SZ surface across the TPB for $\mathrm{CO}-\mathrm{CO}_{2}$ at $800-1000^{\circ} \mathrm{C}$ are oxygen exchange under ordinary $\mathrm{CO}-\mathrm{CO}_{2}$ conditions and carbon exchange 


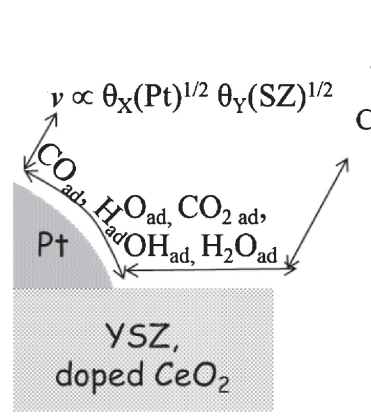

(a) Reaction across TPB. Characteristic with $\mathrm{Pt}$ Electrodes on oxide ion conductors

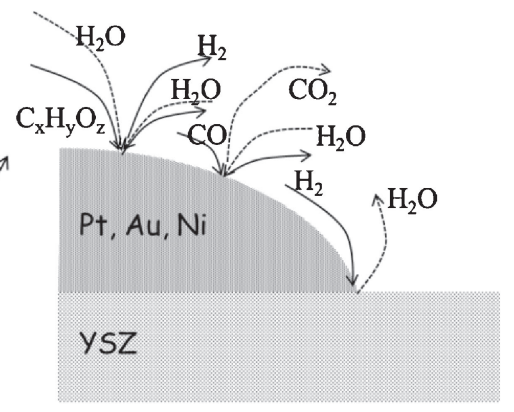

(b) Hydrocarbon decomposition on metal electrodes. Rate determining reaction is the same to hydrogen oxidation.
Figure 4. Typical reaction process in anode atmospheres.

across TPB at the conditions close to carbon deposition. ${ }^{25}$ In the $\mathrm{H}_{2}$ $\mathrm{H}_{2} \mathrm{O}$ atmospheres, $\mathrm{OH}$ exchange between the adsorbed species on $\mathrm{Pt}$ and $\mathrm{SZ}$ becomes the rate determining step. ${ }^{30}$

The important model employed in this analysis is the following hypothesis; Let us consider the cross section of two surface $\mathrm{X}$ and $\mathrm{Y}$ to form the TPB composed of gas phase, surface $X$ and surface $Y$. Species $A$ adsorbs on $X$ with the coverage $\theta_{A}(X)$ and species $B$ adsorbs on $\mathrm{Y}$ with the coverage $\theta_{\mathrm{B}}(\mathrm{Y})$. $\mathrm{A}$ and $\mathrm{B}$ can collide each other only at the TPB where the two surface meet together. The hypothesis is that, when the surface coverage is $\theta$, the one dimensional density at the edge of the surface would be $\theta^{1 / 2}$. That is, the rate of the reaction between $\mathrm{A}$ and $\mathrm{B}$ at the TPB of $\mathrm{XY}$ surfaces would be proportional to $\theta_{\mathrm{A}}(\mathrm{X})^{1 / 2} \theta_{\mathrm{B}}(\mathrm{Y})^{1 / 2}$.

$$
v=k \theta_{\mathrm{A}}(\mathrm{X})^{1 / 2} \theta_{\mathrm{B}}(\mathrm{Y})^{1 / 2}
$$

Based on this hypothesis, $i-V$ relationship and $\sigma_{\mathrm{E}}$ for the porous $\mathrm{Pt} / \mathrm{SZ}$ electrode in $\mathrm{CO}-\mathrm{CO}_{2}$ and $\mathrm{H}_{2}-\mathrm{H}_{2} \mathrm{O}$ environments were well described assuming Langmuir type adsorption of the expected species on Pt and SZ surfaces. ${ }^{25,30}$ Figure 4(a) shows the reaction scheme.

Very interestingly, the $i-V$ relationships observed with $\mathrm{CH}_{4}-\mathrm{H}_{2} \mathrm{O}$ gas mixtures show similar behavior with those in $\mathrm{H}_{2}-\mathrm{H}_{2} \mathrm{O}$ atmospheres. ${ }^{35,37,43}$ Assuming that the decomposition and partial oxidation of $\mathrm{CH}_{4}$ as well as shift reaction take place on Pt surface as shown in Fig. 4(b), Onuma, the author and other members succeeded to explain the reactions, showing that the rate determining reaction is the same to that in $\mathrm{H}_{2}-\mathrm{H}_{2} \mathrm{O}$ system, i.e. the reaction between the adsorbed species on $\mathrm{Pt}$ and those on $\mathrm{SZ}$ across TPB.

\subsection{Surface reaction (dissociative adsorption)—electrode bulk diffusion-electrode/electrolyte interface}

Along with the reaction path via surface diffusion shown by route (1), oxygen atoms diffuse in the electrode as shown by route (3) in Fig. 1. When the electrode is metal, dissolved oxygen diffuses. In oxides, oxygen atoms diffuse in the form of oxide ions or, in some cases, counter anions ${ }^{101}$ and electrons. The diffusion mechanism is called chemical diffusion. Whether the bulk diffusion path predominates or the surface diffusion path predominates is determined by the ratio of surface vs. bulk in the magnitude of diffusivity and also in the length of TPB vs. the area of close contact at the electrode/electrolyte interface. When the electrode is designed to have fine structure so that the interface has relatively smaller contact area and longer TPB, the surface diffusion path may predominate. When the electrode particles experience grain-growth, TPB length decreases while the contact area with SZ surface increase. Then, the bulk diffusion path shows more contribution for oxygen transport between gas phase and electrolyte via electrode. However, it was not easy to distinguish experimentally the reaction path whether via bulk or via surface. The best way to evaluate the contribution of the bulk diffusion path is to prepare the electrode which has no TPB, namely, the dense layered electrode. It was, though, very difficult to prepare and maintain dense electrode at the working high temperatures under varying oxygen potential and/or electrode potential.

The first success to observe the electrode reaction taking place via the bulk diffusion path was done by the present author and his co-workers on $\mathrm{La}_{1-x} \mathrm{Sr}_{x} \mathrm{MnO}_{3}$ film electrodes prepared on PSZ ( $3 \mathrm{~mol} \% \mathrm{Y}_{2} \mathrm{O}_{3}$ doped $\mathrm{ZrO}_{2}$ ) by Pulsed Laser Deposition (PLD) technique, ${ }^{33}$ with the courtesy of NKK company. Experimental work itself was done in early 1991.

Following the first work, many groups, including the author's, started the study of electrode reaction kinetics using the dense PLD oxide film prepared on oxide electrolytes. When the electrode oxide is highly nonstoichiometric with large amount of defects on oxygen sublattice, the bulk diffusion through the electrode is the predominant reaction path. Typical examples are $\mathrm{La}_{1-x} \mathrm{Sr}_{x} \mathrm{CoO}_{3-\delta} 38,40,50,64,68$ in oxidizing atmospheres and doped $\mathrm{CeO}_{2}{ }^{55}$ in reduced atmospheres.

\section{Models for Chemical Capacitance and Time Dependent Properties}

\subsection{Chemical capacitance and its origin \\ 5.1.1 Oxygen dissolution and oxide nonstoichiometry}

In the potentiometric gas sensors with porous electrodes, the EMF of the sensor is determined by the difference in the chemical potential of gaseous component between the reference and working gas electrodes. In oxygen gas sensor for combustion control, EMF is determined by the difference in $\mu_{\mathrm{O}}$ between the combustion gas/ porous $\mathrm{Pt}$ working electrode and the air/porous $\mathrm{Pt}$ reference electrode both on a SZ electrolyte. At the interface of a certain electrode particle and the electrolyte surface, the electrode transports electrons and the electrolyte transports ions along the plane. Therefore, the chemical relaxation along the interface of electrode particle/solid electrolyte is rather smooth and $\mu_{\mathrm{O}}$ at the interface becomes homogeneous rather quickly. However, when gas phase composition changes or temperature changes and there appear a difference in $\mu_{\mathrm{O}}$ between the gas phase and the electrode/solid electrolyte interface, it requires some rate process to re-attain the equilibrium between the gas-phase and the electrode/electrolyte interface. When difference exists in chemical potential between two points, some kind of chemical reaction or chemical diffusion, so to say chemical relaxation, will take place to equilibrate the chemical potential of these two points. That is, the response process of potentiometric chemical sensor associates chemical relaxation. When the response of the sensor is slow, there should be something along the interface which requires substantial chemical process and needs time to relax. The author struck this idea in the study of zirconia sensors in the early 1980's.

In the earliest papers of the author's group, Sasaki ${ }^{17}$ compared the impedance of several porous electrodes of different materials including Pt, $\mathrm{Ag}$, and $\mathrm{La}_{0.5} \mathrm{Sr}_{0.5} \mathrm{CoO}_{3-\delta}$. It was shown that $C_{\mathrm{E}}$ values for $\mathrm{La}_{0.5} \mathrm{Sr}_{0.5} \mathrm{CoO}_{3-\delta}$ and $\mathrm{Ag}$ were more than $10^{-3} \mathrm{~F} \mathrm{~cm}^{-2}$ and were more than one order larger than those with $\mathrm{Pt}$ in various morphologies. Another interesting finding in this paper ${ }^{17}$ was the characteristic shape of complex impedance plots. Porous $\mathrm{Pt}$ electrodes with small $C_{\mathrm{E}}$ of the order less than $10 \mu \mathrm{F} / \mathrm{cm}^{2}$ showed impedance arcs with almost complete half cycles while the impedance arcs for $\mathrm{Ag}$ and $\mathrm{La}_{0.5} \mathrm{Sr}_{0.5} \mathrm{CoO}_{3-\delta}$ were depressed one with almost a quarter of a circle. In equivalent circuit, the former arc can be expressed by $R C$ parallel circuit while the latter can be explained by $R W$ parallel, where $W$ is the Wurburg impedance representing diffusional process. In the relaxation process of $\mathrm{Ag}$ and 


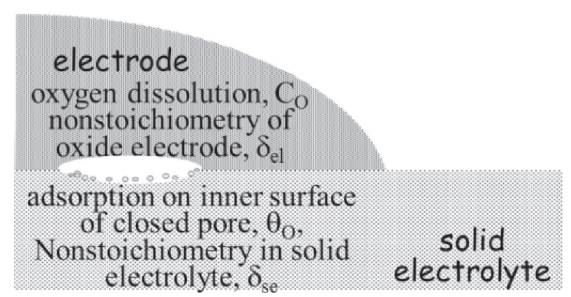

(a) Origin of pseudo (chemical) capacitance: oxygen reservoirs around reaction path

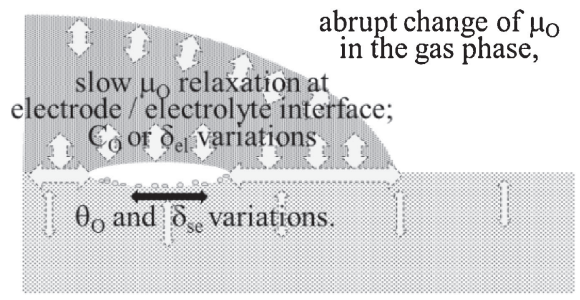

(b) Relaxation of porous gas electrode after abrupt change of gas phase $\mu\left(\mathrm{O}_{2}\right)$; response mechanism of potentiometric gas sensors

Figure 5. Chemical capacitance and response of potentiometric gas sensors.

$\mathrm{La}_{0.5} \mathrm{Sr}_{0.5} \mathrm{CoO}_{3-\delta}$ electrodes on YSZ, the chemical relaxation process of electrode/SZ is controlled by diffusion process. It was concluded that main part of $C_{\mathrm{E}}$ of $\mathrm{Ag}$ electrode is oxygen dissolution process and that of $\mathrm{La}_{0.5} \mathrm{Sr}_{0.5} \mathrm{CoO}_{3-\delta}$ is the variation of oxygen nonstoichiometry in $\mathrm{La}_{0.5} \mathrm{Sr}_{0.5} \mathrm{CoO}_{3-\delta}$.

\subsubsection{Adsorption on the inner surface of closed pores}

As to porous Pt electrodes, with further morphological insight, relationship between $C_{\mathrm{E}}$ and the morphology of contact area of $\mathrm{Pt} /$ YSZ became of interest. The value of $C_{\mathrm{E}}$ for Pt paste electrode is much larger than that of Pt sputtered film electrode. Firing temperature and resulting morphology strongly affect $C_{\mathrm{E}}$; well sintered coherent $\mathrm{Pt} / \mathrm{YSZ}$ interfaces give smaller $C_{\mathrm{E}}$ while highly porous but glass containing paste resulted in larger $C_{\mathrm{E}}$. The origin of $C_{\mathrm{E}}$ for $\mathrm{Pt} / \mathrm{YSZ}$ interface was concluded to be the closed pores at the interface and the specimen was considered to be the adsorbed oxygen on the YSZ surface facing the closed pore. ${ }^{60}$ The closed pore model was confirmed by the Pt/YSZ interface with chemical modification on YSZ by $\mathrm{HF}^{18}$ and on $\mathrm{La}_{0.6} \mathrm{Ca}_{0.4} \mathrm{MnO}_{3-\delta} /$ YSZ interface with different sintering temperature $21,23,24$ for $\mathrm{O}_{2}$ atmospheres.

The impedance and sensor response measurements on $\mathrm{Pt} / \mathrm{YSZ}$ in $\mathrm{CO} / \mathrm{CO}_{2}{ }^{26}$ and $\mathrm{H}_{2} / \mathrm{H}_{2} \mathrm{O}^{28}$ revealed a little bit different picture. That is, when the major component of environmental gas is switched from oxygen molecules to carbon oxides or hydrogen-steam, the chemical species in the pore seemed also switched to the respective gases. This means that "closed pore" is not completely closed but the gas in the "closed pore" seems gradually being exchanged with the outer gas phase, maybe through grain-boundaries or nano-pores connecting the "closed pore"s with outside. Figure 5(a) summarizes the origin of pseudo capacitance.

To obtain reliable reproducible data with porous Pt electrode in $\mathrm{CO} / \mathrm{CO}_{2}$ atmosphere, the author used well-sintered large grain, $\sim 10 \mu \mathrm{m}$, Pt electrode on YSZ. With this electrode, we found clear Wurgburg-type impedance in $\mathrm{CO} / \mathrm{CO}_{2}$ atmospheres. ${ }^{25}$ The relaxation was expected to take place along the interface of $\mathrm{Pt} / \mathrm{SZ}$. However, the obtained results rather indicated that rate determining process was chemical diffusion of oxygen in SZ. It may suggest that the rate of the relaxation process was determined by the relaxation of large closed pore at the interface, indicated in Fig. 5(b) by the black arrow.

\subsection{Response of potentiometric sensor and chemical capacitance}

Figure 5(b) schematically summarizes the chemical relaxation processes expected to take place in the porous electrode of potentiometric oxygen gas sensor after the abrupt gas phase chemical potential change. For the relaxation of $\mu_{O}$ in the metal electrode, dissolved oxygen content should be equilibrated by incorporating or releasing oxygen from the electrode, the nonstoichiometry of oxide electrode and solid electrolyte should also be equilibrated with oxygen incorporation or release. The expected close pores at the interface may be refilled and the inner surface oxygen adsorption should be re-equilibrated with incorporation or liberation of oxygen. These oxygen transport process between the gas phase and the electrode/electrolyte interface involves the rate process including the reaction at the triple phase boundary, the surface diffusion process of adsorbed species on the electrode or electrolyte, and surface adsorption-desorption process of electrode surface. That is, the chemical relaxation process of the electrode/ electrolyte interface requires the same process necessary for the electrode reaction of the fuel cells and electrolytic cells to proceed. The response of the potentiometric gas sensors are determined by the same chemical processes governing the other electrochemical cells.

Since the electrode potential variation accompanies chemical relaxation and hence the mass flow, in principle, we can obtain the rate equation of mass flow from the EMF variation of potentiometric sensors. Using adsorption isotherms for adsorbed layers and reaction rate equation for the chemical processes, the authors tried the analysis of EMF decay curve of sensor response. ${ }^{60,26}$ See the references ${ }^{60}$ for detailed analysis and mathematical techniques. The simple conclusion is, the sensor response time $\kappa / s$ is roughly given by $\sigma_{\mathrm{E}} / C_{\mathrm{E}}$ of the sensing gas electrode on $\mathrm{SE}$.

$$
\kappa=\sigma_{\mathrm{E}} / C_{\mathrm{E}}
$$

\subsection{Chemical capacitance as a tool of kinetic analysis and electrode property evaluation/anomaly in PLD film}

Schematic relaxation process in an electrochemical polarization of a gas electrode system is shown in Fig. 6. During the relaxation, the nonstoichiometry of oxide electrode is considered to vary. This variation is considered to be accompanied by the oxygen incorporation or evolution to affect the $P\left(\mathrm{O}_{2}\right)$ in the gas phase at the gas electrode. The author confirmed such oxygen nonstoichiometry variation in the gas phase from the monitoring data of $P\left(\mathrm{O}_{2}\right)$ in the reactant gas flow by a zirconia oxygen monitor; ${ }^{41}$ Porous $\mathrm{La}_{1-x} \mathrm{Sr}_{x} \mathrm{MnO}_{3-\delta}$ electrode was prepared on SZ surface by slurry painting and the oxygen evolution and incorporation by the porous oxide electrode under transient state was observed from the $P\left(\mathrm{O}_{2}\right)$ variation in the reactant gas flow. The amount of oxygen released or incorporated agreed with the expected value from the nonstoichiometry data determined by high temperature gravimetry and coulometric titration. ${ }^{41}$

Confirmation of nonstoichiometry variation in the oxide electrode with electrode overpotential was also made on PLD films: $\mathrm{La}_{1-x} \mathrm{Sr}_{x} \mathrm{CoO}_{3-\delta}$ electrode film was prepared on gadolinia doped ceria, GDC, by PLD technique and the nonstoichiometry was evaluated from $C_{\mathrm{E}}$. It was found that $C_{\mathrm{E}}$ of the film prepared by PLD was of the same order, however, with obvious negative deviation from the value expected from the reported bulk nonstoichiometry 


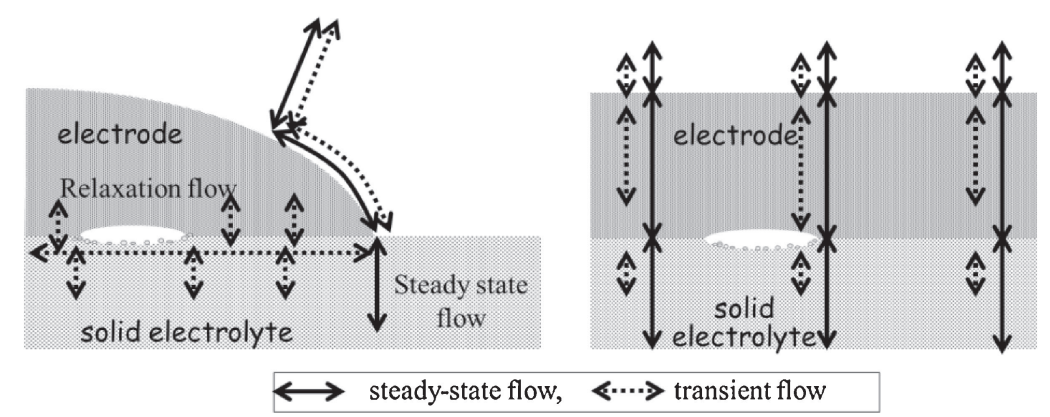

(a) Relaxation of porous electrode under polarization

(b) Relaxation of dense electrode under polarization

Figure 6. Chemical capacitance and steady state vs. transient current.

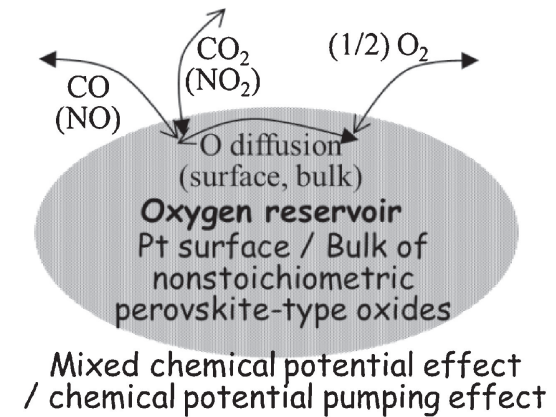

Figure 7. Surface reaction of non-equilibrium gas mixture and chemical potential anomaly.

data. That is, the oxygen deficient nonstoichiometry is much smaller, than the bulk materials. ${ }^{46,68}$ This is contradictory to the electrode prepared by painting slurry, suggesting the problems in the use of PLD techniques. In PLD technique, due to the crystallographic mismatch with substrate, the film showed polymorphism. PLD films are usually very similar to the bulk materials but, in nature, metastable polymorphism the structure of which depends on the substrate of the film during the preparation. ${ }^{102}$

\section{Mixed Chemical Potential Effect/Surface Chemical Potential Anomaly}

\subsection{Mixed chemical potential effect/impurity gas/chemical potential pumping effect}

In many occasions, equilibrium is hardly attained only in the isolated gas phase because there is no catalyst. When catalysts are inserted in the gas, equilibrium is attained essentially on the catalytic surface. Then, on the surface of catalyst, unusual chemical potential may appear under the progress of catalytic reaction. Figure 7 shows the schematics of the catalytic reaction on an oxygen reservoir that can be a surface adsorption layer or an oxide bulk. Under the progress of such catalytic reaction, the oxygen chemical potential is different from the one expected from the majority species in the gas phase. Basically, the oxygen chemical potential is in between the one determined by oxidant gas and that by reductant gas. That can be called mixed chemical potential effect. In some case, this effect causes an unexpectedly large oxygen potential deviation in the catalysts. For example, small amount of $\mathrm{NO}_{2}$ in the oxygen atmosphere give extraordinary high effective oxygen chemical potential in catalysts. ${ }^{103-105}$ This effect was named chemical potential pumping effect, ${ }^{105}$ because high oxygen chemical potential of diluted gaseous specimen, such as $\mathrm{NO}_{2}$, is accumulated in nonstoichiometric oxide to be an effective potential.
This chemical potential mixing effect is observed in chemical sensors as impurity effects. The appearance of this phenomenon in the gas electrode of SE cells is very similar to the mixed potential effect in aqueous electrolyte electrochemistry with charge transfer controlled kinetics. Examples for the chemical potential mixing effect are shown in Fig. $2 .{ }^{65}$ When diluted $\mathrm{H}_{2}-\mathrm{H}_{2} \mathrm{O}$ gas mixtures and diluted $\mathrm{CO}-\mathrm{CO}_{2}$ gas mixtures are introduced on $\mathrm{Au}$ electrode as in Fig. 2, two type redox reaction takes place at different sites, sharing the surface adsorption layer. The oxygen chemical potential on the $\mathrm{Au}$ surface is considered to be fixed at point $\mathrm{A}$ in Fig. 2. When diluted $\mathrm{H}_{2}-\mathrm{H}_{2} \mathrm{O}$ or $\mathrm{CO}-\mathrm{CO}_{2}$ with the compositions in Fig. 2 is introduced into oxygen atmosphere with $P\left(\mathrm{O}_{2}\right)=0.02$ bar, the oxygen potential on Au surface is at the point $\mathrm{B}$ or $\mathrm{C}$. When the gas phase $P\left(\mathrm{O}_{2}\right)$ varies to 0.2 bar, the point $\mathrm{C}$ moves to the point $\mathrm{D}$. Such mixed chemical potential effect may appear as the impurity disturbance of the oxygen gas sensor. ${ }^{26,28}$ One may use this effect to construct gas sensors. ${ }^{32,39,65}$

\subsection{Surface chemical potential anomaly/impurity phase effect/ surface reaction enhancement}

When catalytically active phase for oxygen reduction is dispersed on rather inactive base surface, the surface oxygen potential may become uneven. This effect was found by Sase as the enhancement of oxygen decomposition reaction on perovskite-type $\mathrm{La}_{1-x} \mathrm{Sr}_{x} \mathrm{CoO}_{3}$ oxide electrode surface with the dispersion of $\mathrm{La}_{2-y} \mathrm{Sr}_{y} \mathrm{CoO}_{4}$ phase on it and detailed analysis was reported. ${ }^{52,53,56}$ Conceptually similar effect was already employed by many researchers such as GDC anode dispersed with $\mathrm{Ni}$.

\section{New Experimental Techniques}

\subsection{Morphology control and evaluation}

\subsubsection{Porous electrode}

To determination the electrode reaction path for porous electrodes, it is vitally necessary to know the relationship of electrochemical properties with TPB length and closely contacted area of $\mathrm{WE} / \mathrm{SE}$ interface. A primitive approach was made to estimate the length of triple phase boundary, TPB, of the gas phase/ electrode/solid electrolyte. ${ }^{24}$ From the SEM image of the crosssection of the porous electrode/electrolyte interface, estimation was made for the average diameter of the contact area of electrode particle to the electrolyte surface and the density of the electrode particle. From these parameters, we can obtain the total length of the TPB and the total area of the closely contacted electrode/ electrolyte interface. It was shown that the former is almost proportional to $\sigma_{\mathrm{E}}$ for the perovskite-type manganite while the latter is proportional to $C_{\mathrm{E}} \cdot{ }^{23,24}$ This approach was also applied to GDC anode on YSZ. ${ }^{54}$ 


\subsubsection{Nickel pattern electrode}

In principle, the length of TPB and the area of closely contacted WE/SE interface can be prepared by dense film formation and photolithography. In reality, there exist many difficulties. You can easily prepare conducting films but it is not easy to prepare dense films without pores or cracks. Photolithography may not apply to any materials. The electrode is used at high temperature. When the temperature of the prepared pattern electrode is raised, thermal stress is expected. Films and substrate surface may be roughened due to grain growth.

The author and co-investigators employed Ionized Cluster Beam (ICB) method for dense Ni film on YSZ and somehow succeeded to prepare pattered electrode. ${ }^{29,31,63}$ ICB film is known to attach very strongly to the substrate, because the beam components get energy in between evaporation and ion-implantation. Similar trials have been continued by many groups on ceramic electrodes as well as metal electrodes.

Pattered electrode was also tried by the author's group by preparing the ceramic pellet with metal mesh buried in it. By careful polishing, we can obtain the TPB in plane so that we can observe dynamic TPB in-situ. ${ }^{71,74}$

\subsubsection{Dense film electrode}

Dense film electrode on SE is desirable for model electrode to study the kinetics with bulk diffusion path, as well as the materials for patterned electrodes. The author tried dense Pt and Au electrodes by sputtering and evaporation on YSZ, to find out that the prepared electrodes had high performance as gas electrode, suggesting that the prepared films processed micro-pores or micro-cracks and had large TPB area. ${ }^{17}$ Similar things have often been experienced.

In the latter 1980 s, strong excimer laser became popular and the oxide film preparation by laser ablation technique with excimer laser became established by several research groups including NKK group and high-temperature superconducting oxides were the major target of the research. The $\mathrm{La}_{1-x} \mathrm{Sr}_{x} \mathrm{MnO}_{3+\delta}$, LSMO, film supplied to the authors' group was one of the earliest stage PLD films prepared besides superconductor oxides by NKK. ${ }^{33}$

However, the PLD film has problems. One is the structural deviation from bulk materials, resulting also in the defect structural variation. ${ }^{46,68,102}$ Another is the remaining TPB. Although almost all the data follow the trend expected for dense electrodes ${ }^{33,48}$ at high $P\left(\mathrm{O}_{2}\right)$ of above 0.1 bar at $700-900^{\circ} \mathrm{C},{ }^{33,68}$ some of the data deviate from the trend of dense electrode and rather follow the tendency of the reaction via TPB.

\subsection{New electrochemical probe: POS and micro POS}

EMF of a potentiometric oxygen sensor is determined by the difference in $\mu_{O}$ between WE/SE interface and RE/SE interface. That is, there is no necessity for the SE of potentiometric sensor to be dense. You can measure the oxygen potential of metal surface just touch the end of porous YSZ probe with Pt electrode on the other end exposed to air, and measure the electrostatic potential difference of the Pt electrode and metal to measure the EMF. The EMF represents the surface oxygen potential of metal. This is the concept of Porous Oxygen Sensor (POS). ${ }^{40}$ By modifying AFM apparatus, we prepared micro-POS and determine $\mu_{O}$ profile on the surface of LSMO from TPB of LSMO/SZ to confirm the surface diffusion kinetics. ${ }^{40,51}$

\subsection{In-situ spectroscopy; FTIR/Raman Microspectroscopy/ Xanes}

The author's group developed various micro-size half-cell set-ups for use in variety of in-situ spectroscopic researches. According to the surface diffusion model on $\mathrm{Pt} / \mathrm{SZ}$ interface, ${ }^{17}$ concentration of $\mathrm{O}_{\mathrm{ad}}$ on Pt surface may vary with chemical overpotential, $\eta_{\text {chem }}$. In situ FTIR measurements were made on the surface of Pt near the triple phase boundary as a function of overpotential at $773 \mathrm{~K}$ in the atmosphere of $P\left(\mathrm{O}_{2}\right)=3 \times 10^{4} \mathrm{~Pa}$. Decreasing in the $\mathrm{O}_{\text {ad }}$ peak with cathodic overpotential was confirmed. ${ }^{47,49}$

In situ Raman microspectroscopy was done by preparing the micro fuel cell type set up with transparent silica wall for anode side and specially prepared model nickel electrode with nickel mesh buried into YSZ, as described in 7.1.2. ${ }^{71,74}$ The TPB of Ni/YSZ in $\mathrm{CH}_{4}-\mathrm{H}_{2} \mathrm{O}$ atmospheres were studied. Similar work was also done with Pt/YSZ electrodes. In situ observation of the carbon deposition and development was clearly recorded.

Recently, cation valence state variation from TPB became able to be analyzed utilizing XANES measurements under in-situ conditions, changing incident angles with micro X-ray beam of high power beam radiation facilities. ${ }^{58}$

At present, these in-situ spectroscopies seem still in their initiation stage, and the obtained results are in a manner to confirm the theoretically predicted phenomena. In the near future, these techniques may give us new facts to stimulate the development of physicochemical theories.

\subsection{Semi in-situ measurements; application of SIMS}

In this paper, flux of oxide ion in electrodes and electrolytes is schematically displayed in Fig. 1, Fig. 5(b) and Fig. 6. When we introduce ${ }^{18} \mathrm{O}$ in the gas phase of WE and polarize the WE/SE to cathodic direction, we can observe the sum of natural isotope exchange and ionic transport driven by polarization by the distribution of ${ }^{18} \mathrm{O} \cdot{ }^{42,51}$ The enhancement of surface reaction of $\mathrm{La}_{1-x} \mathrm{Sr}_{x} \mathrm{CoO}_{3-\delta}$ by the dispersion of $\mathrm{La}_{2-x} \mathrm{Sr}_{x} \mathrm{CoO}_{4}$ was confirmed by SIMS. ${ }^{52,53}$ Using tracers and SIMS analysis after quenching, we can visualize the reaction path three dimensionally.

\subsection{In situ high temperature mechanical properties under operation conditions}

Recently, mechanical properties of SOFC or SOEC materials become often measured at high temperatures under operating gas conditions. An example of this type of works the author contributed is the mechanical properties of Ni-YSZ cermet under SOFC operating conditions, showing its very large ductility, ${ }^{76}$ suggesting the reason for the mechanical toughness of SOFCs with Ni-YSZ anode supported type. So far the author has noticed, no report has been published for the mechanical characteristic of high temperature cells under varying chemical overpotential.

\section{Mechanical Properties/Future Prospects}

In this paper, based on the author's studies, overview was made on the gas electrode reaction on solid oxide electrolytes. The electrode reaction is controlled by chemical reaction on the electrode and the overpotential is related to the chemical potential variation at the electrode/electrolyte interface. Due to nonstoichiometry of electrode and electrolytes, lattice volume of electrode and electrolyte varies independently with overpotential. Therefore, the interface may always experience tensile and compressive as well as shear stress. This may cause the replacement of the interface or bending and fracture of the cell itself.

When the reaction takes place, heat comes in or comes out. Thus, at the electrode/electrolyte interface, heat flow always exists and heat flow accompanies temperature gradient. Then, due to thermal expansion, volume of electrode/electrolyte varies with reaction. Thus, when the reaction on the electrode/electrolyte interface is inhomogeneous, there appears thermal flow along the interface, resulting in thermal stresses, and thermal inhomogeneity enhances the local reactivity variation to enhance the inhomogeneity of the local reactivity of the electrode/electrolyte interface.

The important unexplored field of the gas electrode kinetic studies on solid electrolytes is considered "mechanoelectrochemistry", ${ }^{106}$ the field for mechanical aspects of chemical overpotential. 


\section{References}

1. J. E. Bauerle, J. Phys. Chem. Solids, 30, 2657 (1969).

2. H. Yanagida, R. J. Brook, and F. A. Kroeger, J. Electrochem. Soc., 117, 593 (1970).

3. T. H. Etsell and S. N. Flengas, J. Electrochem. Soc., 118, 1890 (1971).

4. T. H. Etsell and S. N. Flengas, Metall. Trans., 3, 27 (1972).

5. S. Pizzini, Fast Ion Transport in Solids (Ed. W. van Gool), North-Holland, Amsterdam, p. 461 (1973).

6. P. Fabry and M. Kleitz, J. Electroanal. Chem., 57, 165 (1974).

7. E. Schouler and M. Kleitz, J. Electroacal. Chem., 64, 135 (1975).

8. A. D. Flanklin, J. Am. Ceram. Soc., 58, 465 (1975).

9. I. Fouletier, P. Fabry, and M. Kleitz, J. Electrochem. Soc., 123, 204 (1976).

10. R. Hartung, Z. Phys. Chem. (Leipzig), 260, 259 (1979).

11. D. Y. Wang and A. S. Nowick, J. Electrochem. Soc., 126, 1155 (1979).

12. D. Y. Wang and A. S. Nowick, J. Electrochem. Soc., 126, 1167 (1979).

13. N. Matsui, Surf. Sci., 86, 353 (1979).

14. H. Obayashi and T. Kudo, Appl. Solid electrolytes (Eds. T. Takahashi and A. Kozawa), JECpress, Ohio, p. 106 (1980).

15. T. M. Gur, I. D. Raistrick, and R. A. Huggins, J. Electrochem. Soc., 127, 2620 (1980).

16. J. Sasaki, J. Mizusaki, S. Yamauchi, and K. Fueki, Solid State Ionics, 3-4, 531 (1981).

17. J. Sasaki, J. Mizusaki, S. Yamauchi, and K. Fueki, Bull. Chem. Soc. Jpn., 54, 1688 (1981)

18. J. Mizusaki, K. Amano, S. Yamauchi, and K. Fueki, Nippon Kagaku Kaishi, 1160 (1985). [in Japanese]

19. J. Mizusaki, K. Amano, S. Yamauchi, and K. Fueki, Solid State Ionics, 22, 313 (1987).

20. J. Mizusaki, K. Amano, S. Yamauchi, and K. Fueki, Solid State Ionics, 22, 323 (1987).

21. J. Mizusaki, H. Tagawa, K. Tsuneyoshi, K. Mori, and A. Sawada, Nippon Kagaku Kaishi, 1623 (1988). [in Japanese]

22. K. Tsuneyoshi, K. Mori, A. Sawata, J. Mizusaki, and H. Tagawa, Solid State Ionics, 35, 263 (1989).

23. J. Mizusaki, H. Tagawa, K. Tsuneyoshi, A. Sawata, M. Katou, and K. Hirano, Denki Kagaku (presently Electrochemistry), 58, 520 (1990).

24. J. Mizusaki, H. Tagawa, K. Tsuneyoshi, and A. Sawata, J. Electrochem. Soc., 138, 1867 (1991).

25. J. Mizusaki, H. Tagawa, Y. Miyaki, S. Yamauchi, K. Fueki, I. Koshiro, and K. Hirano, Solid State Ionics, 53-56, 126 (1992).

26. J. Mizusaki, M. Aoki, Y. Miyaki, S. Yamauchi, and K. Fueki, Denki Kagaku (presently Electrochemistry), 58, 1169 (1990).

27. H. Narita, J. Mizusaki, and H. Tagawa, Denki Kagaku (presently Electrochemistry), 61, 756 (1993).

28. J. Mizusaki, H. Tagawa, K. Isobe, I. Koshiro, M. Tajika, and K. Hirano, Sens. Actuators, B, 13, 121 (1993).

29. J. Mizusaki, H. Tagawa, T. Saito, T. Yamamura, K. Kamitani, K. Hirano, S. Ehara, T. Takagi, T. Hikita, M. Ippommatsu, S. Nakagawa, and K. Hashimoto, Solid State Ionics, 70-71, 52 (1994).

30. J. Mizusaki, H. Tagawa, K. Isobe, M. Tajika, I. Koshiro, H. Maruyama, and K. Hirano, J. Electrochem. Soc., 141, 1674 (1994).

31. J. Mizusaki, H. Tagawa, T. Saito, T. Yamamura, K. Kamitani, K. Hirano, S. Ehara, T. Takagi, T. Hikita, M. Ippommatsu, S. Nakagawa, and K. Hashimoto, J. Electrochem. Soc., 141, 2129 (1994).

32. Z. Yi Can, H. Narita, J. Mizusaki, and H. Tagawa, Solid State Ionics, 79, 344 (1995).

33. J. Mizusaki, T. Saito, and H. Tagawa, J. Electrochem. Soc., 143, 3065 (1996).

34. H. Kamata, A. Hosaka, J. Mizusaki, and H. Tagawa, Denki Kagaku (presently Electrochemistry), 65, 407 (1997).

35. S. Onuma, A. Kaimai, K. Kawamura, Y. Nigara, T. Kawada, J. Mizusaki, H. Inaba, and H. Tagawa, J. Electrochem. Soc., 145, 920 (1998).

36. H. Kamata, A. Hosaka, J. Mizusaki, and H. Tagawa, Solid State Ionics, 106, 237 (1998).

37. S. Onuma, A. Kaimai, K. Kawamura, Y. Nigara, T. Kawada, J. Mizusaki, H. Inaba, and H. Tagawa, J. Electrochem. Soc., 145, 3117 (1998).

38. T. Kawada, K. Masuda, J. Suzuki, A. Kaimai, K. Kawamura, Y. Nigara, J. Mizusaki, H. Yugami, H. Arashi, N. Sakai, and H. Yokokawa, Solid State Ionics, 121, 271 (1999).

39. K. Yashiro, M. Kudo, H. Matsumoto, A. Kaimai, Y. Nigara, T. Kawada, J. Mizusaki, and K. Kawamura, Funtai to Funmatsuyakin, 47, 1026 (2000). [in Japanese]

40. T. Kawada, S. Haga, K. Masuda, K. Kawamura, Y. Nigara, A. Kaimai, J. Mizusaki, and H. Yugami, Trans. Mater. Res. Soc. Jpn., 25, 51 (2000).

41. J. Mizusaki, H. Narita, N. Mori, M. Dokiya, and H. Tagawa, The Korean J. Ceramics, 6, 177 (2000).

42. T. Kawada, T. Horita, N. Sakai, H. Yokokawa, M. Dokiya, and J. Mizusaki, Solid State Ionics, 131, 199 (2000).

43. S. Onuma, A. Kaimai, K. Kawamura, Y. Nigara, T. Kawada, J. Mizusaki, and H.
Tagawa, Solid State Ionics, 132, 309 (2000).

44. K. Yasumoto, N. Mori, J. Mizusaki, H. Tagawa, and M. Dokiya, J. Electrochem. Soc., 148, A105 (2001).

45. K. Yasumoto, M. Shiono, H. Tagawa, M. Dokiya, K. Hirano, and J. Mizusaki, J. Electrochem. Soc., 149, A531 (2002).

46. T. Kawada, J. Suzuki, M. Sase, A. Kaimai, K. Yasahiro, Y. Nigara, J. Mizusaki, K. Kawamura, and H. Yugami, J. Electrochem. Soc., 149, E252 (2002).

47. T. Murai, K. Yashiro, A. Kaimai, H. Matsumoto, Y. Nigara, T. Kawada, and J. Mizusaki, Trans. Mater. Res. Soc. Jpn., 29, 3439 (2004).

48. M. Sase, D. Ueno, K. Yashiro, A. Kaimai, T. Kawada, and J. Mizusaki, J. Phys. Chem. Solids, 66, 343 (2005).

49. T. Murai, K. Yashiro, A. Kaimai, T. Otake, H. Matsumoto, T. Kawada, and J. Mizusaki, Solid State Ionics, 176, 2399 (2005).

50. M. Sase, J. Suzuki, K. Yashiro, T. Otake, A. Kaimai, T. Kawada, J. Mizusaki, and H. Yugami, Solid State Ionics, 177, 1961 (2006).

51. T. Kawada, M. Sase, M. Kudo, K. Yashiro, K. Sato, J. Mizusaki, N. Sakai, T. Horita, K. Yamaji, and H. Yokokawa, Solid State Ionics, 177, 3081 (2006).

52. M. Sase, K. Yashiro, K. Sato, J. Mizusaki, T. Kawada, N. Sakai, K. Yamaji, T. Horita, and H. Yokokawa, Solid State Ionics, 178, 1843 (2008).

53. M. Sase, F. Hermes, K. Yashiro, K. Sato, J. Mizusaki, T. Kawada, N. Sakai, and H. Yokokawa, J. Electrochem. Soc., 155, B793 (2008).

54. T. Nakamura, T. Kobayashi, K. Yashiro, A. Kaimai, T. Otake, K. Sato, J. Mizusaki, and T. Kawada, J. Electrochem. Soc., 155, B563 (2008).

55. T. Nakamura, K. Yashiro, A. Kaimai, T. Otake, K. Sato, T. Kawada, and J. Mizusaki, J. Electrochem. Soc., 155, B1244 (2008).

56. K. Yashiro, T. Nakamura, M. Sase, F. Hermes, K. Sato, T. Kawada, and J. Mizusaki, Electrochem Solid St, 12, B135 (2009).

57. S. Akoshima, M. Oishi, K. Yashiro, K. Sato, and J. Mizusaki, Solid State Ionics, 181, 240 (2010).

58. K. Shinoda, S. Suzuki, K. Yashiro, J. Mizusaki, T. Uruga, H. Tanida, H. Toyokawa, Y. Terada, and M. Takagaki, Surf. Interface Anal., 42, 1650 (2010).

59. E.-C. Shin, P.-A. Ahn, H.-H. Seo, J.-M. Jo, S.-D. Kim, S.-K. Woo, J. H. Yu, J. Mizusaki, and J.-S. Lee, Solid State Ionics, 232, 80 (2013).

60. J. Mizusaki, K. Amano, S. Yamauchi, and K. Fueki, Proc. Internat'l Meeting Chemical Sensors (Analytical Chem. Monogr., 16) (Ed. T. Seiyama et al.), Kodansha/Elsevier, Tokyo/Amsterdam, p. 279 (1983).

61. J. Mizusaki and H. Tagawa, SOFC Oxygen Electrodes: Materials \& Reaction -A Consideration on the Possibility of the Chemical Diffusion Controlled Reaction-, in: Proc. International Symp. on SOLID OXIDE FUEL CELLS, Nagoya, Japan November 13-14, 1989 (Ed. O. Yamamoto et al.), Science House Co. Ltd., Tokyo, p. 107 (1990).

62. J. Mizusaki, H. Tagawa, M. Kato, K. Hirano, A. Sawata, and K. Tsuneyoshi, Proc. 2nd Internat'l Symp. Solid Oxide Fuel Cells, July 2-5, 1991, in Athens, Greece (Ed. F. Gross et al.), Rep. EUR 13546EN, Commission of European Communities, p. 487 (1991).

63. J. Mizusaki, T. Yamamura, N. Mori, H. Tagawa, K. Hirano, S. Ehara, T. Takagi, M. Hishinuma, H. Sasaki, T. Sogi, Y. Nakamura, and K. Hashimoto, Proc. 17th Internat'l Symp. Mat. Sci.: High Temp. Electrochem. Ceramics and Metals (Ed. F. W. Poulsen et al.), Riso National Lab., Rosklde, Denmark, p. 363 (1996).

64. K. Masuda, A. Kaimai, K. Kawamura, Y. Nigara, T. Kawada, J. Mizusaki, H. Yugami, and H. Arashi, Proc. 5th International Symp. SOFC (Ed. U. Stimming, S. C. Singhal, H. Tagawa, and W. Lehnett), ECS Proc. Vol. 97-18, p. 473 (1997).

65. J. Mizusaki, T. Kawada, A. Kaimai, Y. Nigara, K. Kawamura, and H. Matsumoto, Chemical Sensors IV (Ed. M. Butler, N. Yamazoe, P. Vanysek, and M. Aizawa), ECS Proc. Vol. 99-23, Electrochem. Soc. Inc., p. 275 (1999).

66. K. Yasumoto, N. Mori, J. Mizusaki, H. Tagawa, and M. Dokiya, Solid Oxide Fuel Cells (SOFC VI) (Ed. S. C. Singhal and M. Dokiya), Electrochemical Soc. Proc. Vol. 99-19, The Electrochem. Soc., Inc, p. 335 (1999).

67. T. Kobayashi, L.-Q. Han, A. Kaimai, K. Yashiro, K. Kawamura, Y. Nigara, T. Kawada, and J. Mizusaki, Proceedings Volume of International Symposium on Fuel Cells for Vehicles (Ed. O. Yamamoto, Y. Takeda, S. Noda, S. Kawatsu, and N. Imanishi), orgnized by The Commmittee of Battery Technology, The Electrochemical Society of Japan, Nagoya Congress Center, Japan November 20-22, 2000, p. 17 (2000).

68. T. Kawada, M. Sase, J. Suzuki, K. Masuda, K. Yashiro, A. Kaimai, Y. Nigara, J. Mizusaki, K. Kawamura, and H. Yugami, Solid Oxide Fuel Cells, VII (SOFC VII) (Ed. H. Yokokawa and S. C. Singhal), Electrochemical Soc. Proc. Vol. 2001-16, The Electrochem. Soc., Inc. June 3-8, 2001 Epochal Tsukuba, Tsukuba, Japan, p. 529 (2001).

69. F. Z. Boulenouar, K. Yashiro, M. Oishi, A. Kaimai, Y. Nigara, K. Kawada, and J. Mizusaki, Solid Oxide Fuel Cells, VII (SOFC VII) (Ed. H. Yokokawa and S. C. Singhal), Electrochemical Soc. Proc. Vol. 2001-16, The Electrochem. Soc., Inc. June 3-8, 2001 Epochal Tsukuba, Tsukuba, Japan, p. 759 (2001).

70. K. Yasumoto, J. Mizusaki, H. Itoh, S. Wang, H. Tagawa, and M. Dokiya, Solid Oxide Fuel Cells (SOFCVIII) (Ed. S. C. Singhal and M. Dokiya), Electrrochemical Soc. Proc. Vol. 2003-07, The Electrochem. Soc., Inc., p. 458 (2003).

71. K. Yashiro, K. Takeda, T. Taura, T. Otake, A. Kaimai, Y. Nigara, T. Kawada, and J. Mizusaki, Solid Oxide Fuel Cells (SOFCVIII) (Ed. S. C. Singhal and M. Dokiya), Electrrochemical Soc. Proc. Vol. 2003-07, The Electrochem. Soc., Inc., p. 714 (2003). 
72. K. Yashiro, T. Nakamura, A. Kaimai, T. Otake, T. Kawada, and J. Mizusaki, Solid Oxide Fuel Cells (SOFC IV) (Ed. S. C. Singhal and J. Mizusaki), Electrochemical Soc. Proc. Vol. 2005-07, The Electrochem. Soc., Inc., p. 1369 (2005).

73. Y. Nakagawa, K. Yashiro, K. Sato, T. Kawada, and J. Mizusaki, Solid Oxide Fuel Cells 10 (SOFC-X) (Ed. K. Eguchi, S. C. Singhal, H. Yokokawa, and J. Mizusaki), ECS Transactions Vol. 7 No. 1 ISBN 978-1-56677-554-0, 7(1), p. 1373 (2007).

74. K. Yashiro, M. Takase, K. Sato, T. Kawada, and J. Mizusaki, ECS Trans., 16(51), 213 (2009).

75. J. Mizusaki, Proceedings of the 12th Asian Conference on Solid State Ionics, ISBN 978-7-5629-3159-1, Wuhan University of Technology, 12, p. 473 (2010).

76. S. Sukino, S. Watanabe, K. Sato, T. Kawada, J. Mizusaki, and T. Hashida, ECS Trans., Solid Oxide Fuel Cells-16 (SOFC-XII), 35(1), 1473 (2011).

77. J. Mizusaki, Denki Kagaku (presently Electrochemistry), 57, 208 (1989). [in Japanese]

78. J. Mizusaki, Hyomen, 27, 977 (1989). [in Japanese]

79. J. Mizusaki, Denki Kagaku (presently Electrochemistry), 62, 386 (1994). [in Japanese]

80. J. Mizusaki, Denki Kagaku (presently Electrochemistry), 62, 772 (1994). [in Japanese]

81. J. Mizusaki, Ceramics, 29, 1015 (1994). [in Japanese]

82. J. Mizusaki, Solid State Ionics, 86-88, 1335 (1996).

83. J. Mizusaki, Kikan Kagaku-Sosetsu, 49, 206 (2001). [in Japanese] ISBN 4-76222989-X.

84. J. Mizusaki, T. Kawada, K. Yashiro, and M. Sase, Zairyo no Kagaku to Kogyo, 39, 63 (2002). [in Japanese]

85. J. Mizusaki and K. Yashiro, Nano-Mega Sclae Flow Dynamics in Energy Systems, The 21st Century COE Program, International COE of Flow Dynamics, Lecture Series, Vol. 9. (Ed. S. Maruyama), Tohoku Univ. Press, Vol. 9, p. 39 (2008).

86. J. Mizusaki, Seramikkusu kinouka handbook, p. 268 NTN Tokyo, (2011). [in Japanese]

87. J. Mizusaki, Denki-Kagaku Binran $6^{\text {th }}$ ed., p. 284 Maruzen, Tokyo (2013). [in Japanese]

88. J. Mizusaki, Leading Edge of Materials and Systems Development for Next- generation Fuel Cells (Ed. T. Kikuchi), CMC, Tokyo, p. 67 (2013), ISBEN9874-7813-0810-4. [in Japanese]

89. J. Mizusaki, New Research Trends of Fluorite-Based Oxide Materials (Ed. J. Mizusaki and A. Nakamura), Nova New York, p. 1 (2014), ISBN 978-1-63117350-9.

90. M. Kleitz, Solid State Ionics, 3-4, 513 (1981).

91. H. Obayashi and H. Okamoto, Solid State Ionics, 3-4, 631 (1981).

92. D. Braunstein, D. S. Tannhauser, and I. Reiss, J. Electrochem. Soc., 128, 82 (1981).

93. D. Y. Wang and A. S. Nowick, J. Electrochem. Soc., 128, 55 (1981).

94. M. J. Verkerk, M. W. J. Nanmink, and A. j. Burgraaf, J. Electrochem. Soc., 130, 70 (1983).

95. M. J. Verkerk and A. J. Burgraaf, J. Electrochem. Soc., 130, 78 (1983).

96. M. Kleitz, E. Siebert, and J. Feuletier, Chemical Sensors (Ed. T. Seiyama et al.), Kodansha/Elsevier (Tokyo/Amsterdam), p. 262 (1983).

97. S. B. Adler, Chem. Rev., 104, 4791 (2004).

98. E. V. Tsipis, V. Vladislav, and V. Kharton, J. Solid State Electrochem., 12, 1367 (2008).

99. J. Mizusaki, N. Mori, H. Takai, Y. Yonemura, H. Minamiue, H. Tagawa, M. Dokiya, H. Inaba, K. Naraya, T. Sasamoto, and T. Hashimoto, Solid State Ionics, 129, 163 (2000).

100. J. Mizusaki, H. Nambu, C. Nakao, H. Tagawa, H. Minamiue, and T. Hashimoto, Proc. 4th International Symp. SOFC, ECS Proc. Vol. 95-1, p. 444 (1995).

101. S. Miyoshi, A. Kaimai, H. Matsumoto, K. Yashiro, Y. Nigara, T. Kawada, and J. Mizusaki, Solid State Ionics, 175, 383 (2004).

102. T. Nakamura, D. Henmi, K. Iwamoto, N. Hirai, M. Sase, A. Unemoto, F. Horikiri, Y. Mori, K. Sato, K. Yashiro, T. Kawada, and J. Mizusaki, Electrochemistry, this issue in press (2014).

103. K. Yashiro, S. Onuma, M. Sase, A. Kaimai, T. Otake, H. Matsumoto, T. Kawada, and J. Mizusaki, Solid State Ionics, 176, 2411 (2005).

104. J. Mizusaki, M. Hasei, Y. Yonemura, H. Ohama, and H. Tagawa, Trans. IEE Japan, 118-E, 161 (1998).

105. J. Mizusaki, H. Ohama, K. Yashiro, and T. Kawada, Electrochemistry, 74, 949 (2006).

106. K. Sato, private communication. 